\title{
Solubility and Diffusivity of Hydrogen in Vanadium and its Alloys around Room Temperature
}

\author{
By S. Tanaka* and H. Kimura**
}

\begin{abstract}
The solid solubility in equilibrium with hydride and the diffusion coefficient of hydrogen around room temperature are determined in pure vanadium and its alloys. Both determinations are made with the resistivity measurement. The solid solubility is increased by the addition of $\mathrm{Ti}$ and $\mathrm{Zr}$, slightly increased by $\mathrm{Mo}$, not affected by $\mathrm{Nb}, \mathrm{Cr}$ or $\mathrm{Fe}$ and slightly decreased by $\mathrm{Cu}$. The diffusion coefficient is decreased by $\mathrm{Ti}$ and $\mathrm{Zr}$, while other elements investigated have no effect. The effects of $\mathrm{Ti}$ and $\mathrm{Zr}$ may be due to binding between hydrogen atoms and the solvent atoms in dilute solutions. The H-Ti binding energy is estimated to be about $0.15 \mathrm{eV}$. The origin of the H-Ti and $\mathrm{H}-\mathrm{Zr}$ binding is likely to be electronic.
\end{abstract}

(Received July 30, 1979)

\section{Introduction}

Vanadium is a potential material for high temperature and nuclear uses; vanadium alloys are expected to be used for the first wall material of a nuclear fusion reactor. In these applications, the permeability of hydrogen and its isotopes is one of the technological problems, and much effort has been made to measure the permeability, solubility(1)(2) and diffusivity ${ }^{(3)}$ of hydrogen and its isotopes in vanadium and its alloys at high temperatures. Eguchi and Morozumi $^{(2)}$ have shown that the gas solubility of hydrogen between 827 and $1427 \mathrm{~K}$ is increased by titanium addition, while addition of chromium, iron and cobalt decreases it. It has also been reported that addition of niobium, chromium, iron or titanium decreases the diffusivity of hydrogen in vanadium above $900 \mathrm{~K}$, while 40 at \% titanium addition increases $i^{(3)}$. They have discussed that the effect of alloying on the solubility is related to the electron state density at the Fermi surface, and the effect on the diffusivity to the proton screening by electrons ${ }^{(4)}$.

Another technological problem is the embrittlement below room temperature caused by hydride ${ }^{(5)}$. It has been shown that the

* Graduate School, Tohoku University, Sendai 980, Japan.

** Research Institute for Iron, Steel and Other Metals, Tohoku University, Sendai 980, Japan. initiation and propogation of a crack are related to the hydrogen solid solubility and diffusivity ${ }^{(6)}$, and hence an extensive research is needed on the hydrogen behavior at near room temperature. The solid solubility of hydrogen in vanadium around room temperature has been determined by electrical resistance change $^{(7)(8)(10)}$, optical observation ${ }^{(9)}$ and internal friction ${ }^{(11) \sim(13)}$ measurements. The measured solubility somewhat depends on the experimental technique. The solubility data measured with resistometry by various investigators accord with each other within the experimental error, while results with internal friction do not agree with each other so well. Hence, the resistivity technique is considered to be more reliable. The diffusivity of hydrogen and deuterium in vanadium around room temperature has been measured by means of the Gorsky effect ${ }^{(14)(15)}$, electrical resistivity change $^{(7)}$ and electrochemical methods ${ }^{(16)}$. The first two methods measure solely the bulk diffusion of hydrogen, but in the third method the result may be influenced by the existence of surface oxide layer. No measurement of diffusivity or solubility around room temperature has been reported on vanadium base alloys in spite of its practical importance. At low temperatures, trapping of hydrogen by solute atoms is expected to exist in a dilute solid solution and it may give an effect different from the electronic effect in concentrated alloys. Hence, dilute alloys should also be investigated. 
The purpose of the present research is to measure, by electrical resistivity technique, the hydrogen diffusivity and solubility in pure vanadium and vanadium base alloys around room temperature to offer some basic data to the vanadium alloy metallurgy.

\section{Experimental}

\section{Specimen preparation}

Two grades of pure vanadium were used, i.e., MRC Marz Grade (MRC-V) and Nihon Gaishi Inc. (N-V) vanadium. The nominal purity of MRC-V is $99.95 \%$ and that of raw material of $\mathrm{N}-\mathrm{V}$ is $99.8 \%$. Electron beam melting under $10^{-3} \mathrm{~Pa}$ increased the purity of $\mathrm{N}-\mathrm{V}$ up to $99.9 \% . \mathrm{N}-\mathrm{V}$ is then arc-melted, swaged and drawn to wire. Finally the wire was chemically polished to about $120 \mu \mathrm{m}$ in diameter. All of the pure vanadium wire are annealed by Joule heating under a vacuum of $10^{-6}-10^{-7} \mathrm{~Pa}$. The final purity, measured by the resistivity ratio (RRR), is $20-50$ for the all vanadium. The impurity concentration is estimated from the resistivity at $4.2 \mathrm{~K}$ to be 800 to 1500 at.ppm. The $\mathrm{Zr}$ foil treatment was tried to increase the purity ${ }^{(13)(17)}$ of $\mathrm{N}-\mathrm{V}$, but was not effective. Interstitial impurities, mainly $\mathrm{O}, \mathrm{N}$, should have been reintroduced in the course of UHV annealing after $\mathrm{Zr}$ foil treatment and wire drawing ${ }^{(18)}$.

Vanadium base alloys were made from $\mathrm{N}-\mathrm{V}$. Alloying elements are seven transition metals listed in Table 1, among which $\mathrm{V}-5 \mathrm{at} \% \mathrm{Ti}$, $-5 \mathrm{at} \% \mathrm{Cr}$ and $-5 \mathrm{at} \% \mathrm{Nb}$ were offered by Eguchi and Morozumi ${ }^{(2)(3)}$. Since titanium was found to affect the solubility and diffusivity of hydrogen most effectively, nine V-Ti alloys are made as listed in Table 2. The intended and analysed concentration of alloying elements are also tabulated. Alloys were made by arcmelting, and then formed to wire of about $120 \mu \mathrm{m}$ in diameter with the same procedure as pure vanadium. They were annealed at $1273 \mathrm{~K}$ for $29 \mathrm{~h}$ under a vacuum of $10^{-6}-10^{-7} \mathrm{~Pa}$. After annealing the heating current was cut off, and the specimen was cooled down to room temperature by heat radiation (the cooling rate was about $500 \mathrm{~K} / \mathrm{s}$ ). This procedure was to
Table 1 Chemical analysis of alloys.

\begin{tabular}{llcc}
\hline \hline Alloy & $\begin{array}{c}\text { Alloying } \\
\text { element }\end{array}$ & $\begin{array}{c}\text { Mixed } \\
\text { content } \\
(\text { at } \%)\end{array}$ & $\begin{array}{c}\text { Analysed } \\
\text { content } \\
(\text { at } \%)\end{array}$ \\
\hline & $\mathrm{Nb}$ & 1.00 & 1.02 \\
$\mathrm{Ti}$ & 1.00 & 1.00 \\
$\mathrm{~V}-1$ at $\% \mathrm{M}$ & $\mathrm{Zr}$ & 1.00 & 1.04 \\
& $\mathrm{Cr}$ & 1.00 & 1.00 \\
& $\mathrm{Mo}$ & 1.00 & 1.02 \\
& $\mathrm{Fe}$ & 1.00 & 0.977 \\
& $\mathrm{Cu}$ & 1.00 & 0.972 \\
\hline & $\mathrm{Nb}$ & 5.02 & 4.77 \\
& $\mathrm{Ti}$ & 5.21 & 4.80 \\
& $\mathrm{Cr}$ & 5.19 & 4.48 \\
\hline \hline
\end{tabular}

* offered by T. Eguchi and S. Morozumi (Ref. (3))

Table 2 Chemical analysis of V-Ti alloys.

\begin{tabular}{ccc}
\hline Alloy & $\begin{array}{c}\text { Mixed Ti } \\
\text { content (at \%) }\end{array}$ & $\begin{array}{c}\text { Analysed Ti } \\
\text { content (at\%) }\end{array}$ \\
\hline V-0.2 at \%Ti & 0.20 & 0.21 \\
V-0.4 at \%Ti & 0.41 & 0.38 \\
V-1.0 at \%Ti & 1.00 & 1.00 \\
V-1.8 at \%Ti & 1.79 & 1.90 \\
V-3.9 at \%Ti & 3.89 & 3.94 \\
V-5.2 at \%Ti & 5.21 & 4.80 \\
V-8.9 at $\% \mathrm{Ti}$ & 8.88 & 9.17 \\
$\mathrm{~V}-13.7$ at $\% \mathrm{Ti}$ & 13.7 & 13.3 \\
$\mathrm{~V}-18.7$ at $\% \mathrm{Ti}$ & 18.7 & 19.1 \\
\hline \hline
\end{tabular}

obtain a homogeneous solid solution. The homogeneity of alloying elements are investigated with electron probe microanalysis (EPMA). All the annealed wires were of bamboo type grain structure except for $\mathrm{V}-\mathrm{Ti}$ systems, and the grain size is 100 to $300 \mu \mathrm{m}$. The grain size of V-Ti alloys was below $100 \mu \mathrm{m}$.

\section{Methods of measurement}

\section{(1) Solid solubility}

Hydrogen was introduced into specimens electrolytically. In the course of hydrogen charging the increase in electrical resistivity was measured at intervals. To know the hydrogen concentration from the electrical resistivity increase, the amount of charged hydrogen was analysed by the argon gas carrier fusion-gas chromatographic method ${ }^{(19)}$. The specimens used for analysis are about $450 \mu \mathrm{m}$ in diameter prepared in the same way as for other specimens. The time-hydrogen concentra- 
tion relation depends on charging conditions, i.e., the electrolytic solution, the anode materials and the surface condition of the specimen. Among several charging conditions, the following was found to be best in reproducibility, i.e., graphite electrode as anode, a $0.1 \mathrm{~N} \mathrm{H}_{2} \mathrm{SO}_{4}-\mathrm{H}_{2} \mathrm{O}$ solution above 273 $\mathrm{K}$ and a $0.1 \mathrm{~N} \mathrm{H}_{2} \mathrm{SO}_{4}-\mathrm{CH}_{3} \mathrm{OH}-\mathrm{H}_{2} \mathrm{O}$ or a $0.1 \mathrm{~N}$ $\mathrm{H}_{2} \mathrm{SO}_{4}-\mathrm{C}_{2} \mathrm{H}_{5} \mathrm{OH}$ solution below $273 \mathrm{~K}$ as the electrolyte, and the charging current of $1000 \mathrm{~A} /$ $\mathrm{m}^{2}$. The hydrogen charging curve in pure vanadium is shown in Fig. 1. The electrical resistivity increases linearly with time at the beginning, and then deviation from linearity occurs. This point of deviation is defined as the hydrogen solid solubility at the charging temperature.

\section{(2) Diffusivity}

\section{(a) Measurement}

A specimen was welded with potential leads deviding the specimen into five sections and coated with lacquer except at the central portion. The whole specimen was immersed in the electrolytic solution with the uncovered

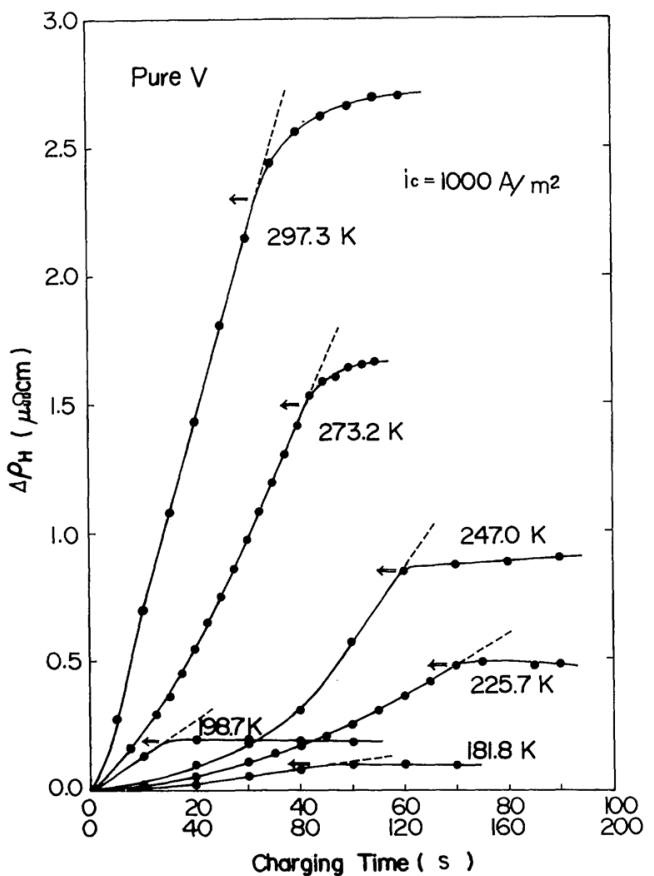

Fig. 1 Resistivity increase with hydrogen charging at various temperatures. The solubility limit defined in the text is shown by the arrows. portion in direct contact with the solution, and charged with hydrogen. After charging, hydrogen diffuses into the coated and hence uncharged region, and the resistivity of those portion is increased. The local resistivity was measured as a function of time. The diffusion coefficient of hydrogen is calculated with the distance-time-resistivity relation. This method is similar to that used by Westlake, Ockers and $\operatorname{Regan}^{(20)}$, which is a refinement of the method originated by Merisov, Khotkevich and Karnus $^{(21)}$. However, Westlake et al. used only two portions to calculate the diffusion coefficient, while five portions are used in the present experiment.

The electrolyte is the same as that used in the solid solubility measurement. The diffusion anneal was performed in an oil bath and a water bath above room temperature, and at and below $273 \mathrm{~K}$ the electrolyte bath is also used for the anneal. The diffusion anneal temperature is controlled within $\pm 0.05 \mathrm{~K}$.

(b) Calculation of the diffusion coefficient

Because of the very small specimen diameter the radial distribution of hydrogen can be neglected, and the problem is treated as one dimensional. If the diffusion coefficient $D$ is independent of the hydrogen concentration and the total amount of hydrogen is conserved during the diffusion anneal, the diffusion equation is

$$
\begin{aligned}
& \frac{\partial c}{\partial t}=D \frac{\partial^{2} c}{\partial x^{2}}, \\
& \text { with } c=c_{0} \text { at }|x|<h \text { and } \\
& \qquad c=0 \text { at }|x|>h \text { for } t=0,
\end{aligned}
$$

where $c_{0}$ and $2 h$ are the amount of hydrogen charged and the length of the uncoated portion of the specimen, respectively. The solutions of eq. (1) are as follows ${ }^{(22)}$ :

For an infinitely long specimen,

$$
c(x, t)=\frac{c_{0}}{2}\left(\operatorname{erf} \frac{h-x}{2 \sqrt{D t}}+\operatorname{erf} \frac{h+x}{2 \sqrt{D t}}\right) .
$$

For a finite specimen,

$$
\begin{aligned}
& c(x, t) \\
& =\frac{c_{0}}{2} \sum_{n=-\infty}^{\infty}\left(\operatorname{erf} \frac{h+2 n L-x}{2 \sqrt{D t}}+\operatorname{erf} \frac{h-2 n L+x}{2 \sqrt{D t}}\right),
\end{aligned}
$$


where $L$ denotes the specimen length and eq. (3) is solved under the boundary condition that $\partial c / \partial x=0$ at $x= \pm L$. The hydrogen distribution changes with time as schematically shown in Fig. 2. This is for the case of a finite specimen. The hydrogen concentration is measured as the resistivity change; the average concentration in a portion is proportional to the mean resistivity increase of the portion,

$$
\begin{aligned}
\rho(t) & =\rho_{\mathrm{H}} \cdot \bar{c}(t) \\
& =\frac{\rho_{\mathrm{H}}}{b-a} \int_{a}^{b} c(x, t) \mathrm{d} x,
\end{aligned}
$$

where $\rho_{\mathbf{H}}$ is resistivity increase due to a unit concentration of hydrogen, $1.12 \mu \Omega \mathrm{cm} /$ at $\% \mathrm{H}$ as will be described later.

The diffusion constant is obtained by fitting the calculated curve to the experimental one. At the beginning of the diffusion anneal the system can be regarded as being infinite and hence eq. (2) is used. The diffusion coefficient is calculated independently for five parts of specimen. However, the values for four parts except for the central part are adopted because the diffusion coefficient obtained for the central

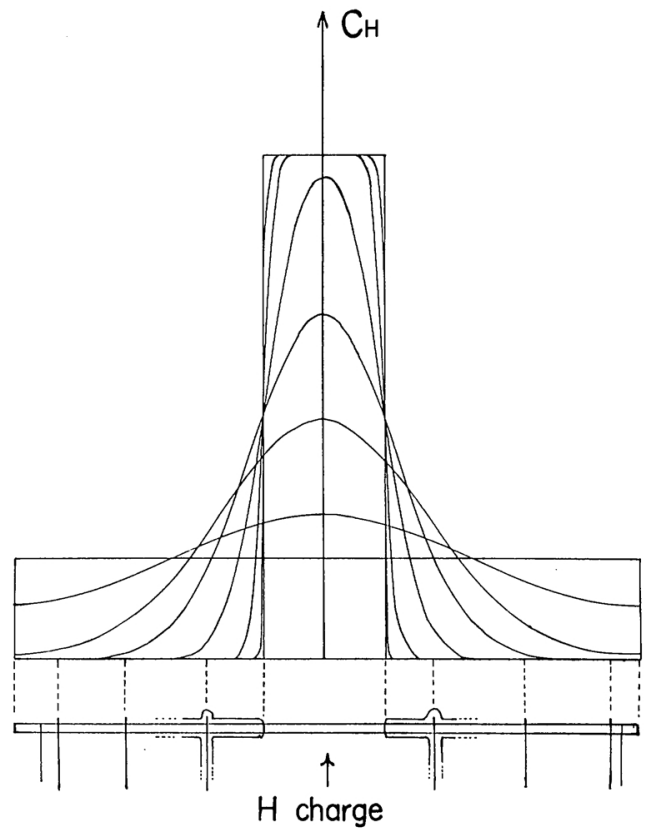

Fig. 2 Schematic diagram of diffusion annealing. Hydrogen concentration gradually becomes uniform along the specimen with annealing time. part sometimes differs from those for other parts.

\section{Experimental Results}

\section{Solid solubility of hydrogen}

(1) The concentration vs resistivity relation of hydrogen in vanadium alloys

The contribution of hydrogen to the electrical resistivity, $\rho_{\mathrm{H}}$, is determined to be $1.12 \mu \Omega \mathrm{cm} /$ at $\%$ from the observed electrical resistivity increase at room temperature and chemically analysed hydrogen concentrations as shown in Fig. 3. The data fall well on the straight line of $1.12 \mu \Omega \mathrm{cm} / \mathrm{at} \%$ for hydrogen concentrations below about 1.5 at \%, except for $\mathrm{V}-1.0$ at $\% \mathrm{Zr}$ alloys. The $\rho_{\mathrm{H}}$ value agrees with that reported by Westlake $^{(8)}$ for pure vanadium-hydrogen system. However, it differs from other authors' values $^{(23) \sim(25)}$. The reason for the difference will not be discussed here. The purpose of the

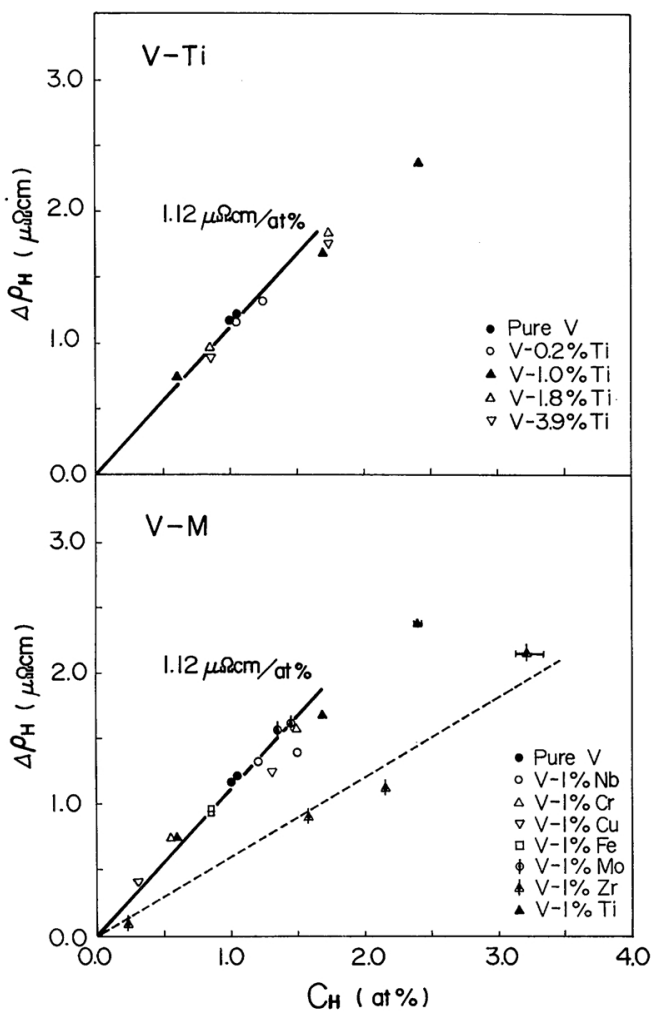

Fig. 3 The relation between hydrogen concentration and resistivity increase. 
present research is not to obtain the absolute value of the solubility, but to find the alloying effect on the hydrogen solid solubility; relative values are important. Hence, the present $\rho_{\mathrm{H}}$ value is used to convert the electrical resistivity change to the hydrogen concentration. It is noteworthy that the same $\rho_{\mathbf{H}}$ value holds even in the vanadium base alloys. The anomaly of $\mathrm{V}-\mathrm{Zr}$ alloys is likely to be due to segregation of $\mathrm{Zr}$ atoms as described later. A reliable $\rho_{\mathrm{H}}$ cannot be determined in $\mathrm{V}-\mathrm{Zr}$ alloys. Hence, the same $\rho_{\mathrm{H}}$ is tentatively used to calculate the hydrogen concentration in $\mathrm{V}-\mathrm{Zr}$ alloys.

\section{(2) Solubility}

The deviation from linearity in the timeresistivity curve corresponds to the precipitation of hydrides, because in general solute atoms in precipitates contribute less to the resistivity than in a solid solution. The measured solid solubility of hydrogen is shown in Fig. 4. This is in good agreement with other investigators' results $^{(7) \sim(10)}$. The agreement confirms the validity of the present method.

Hydrogen solid solubilities in vanadium1.0 at $\%$ transition metal alloys are shown in Fig. 5. The concentration shown in the right

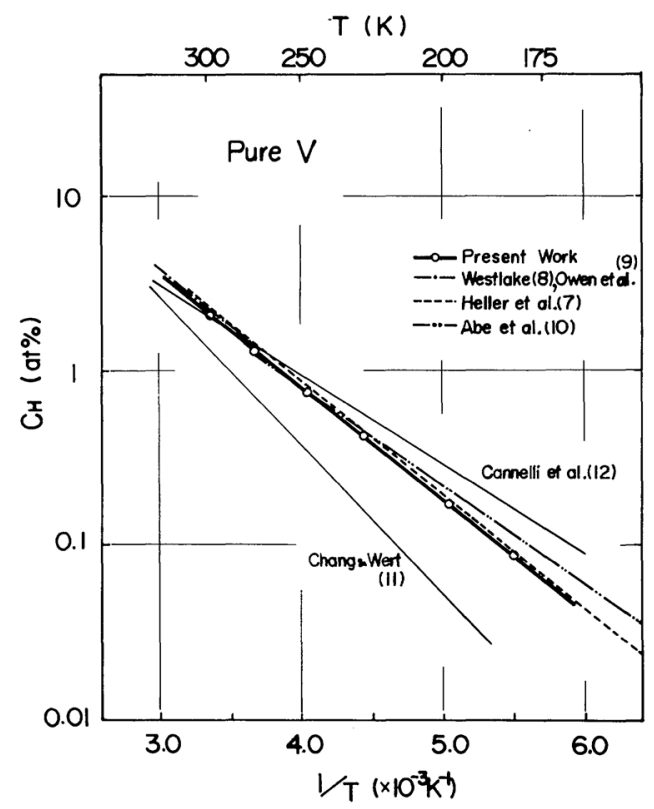

Fig. 4 The solid solubility of hydrogen in pure vanadium in comparison with other author's data.

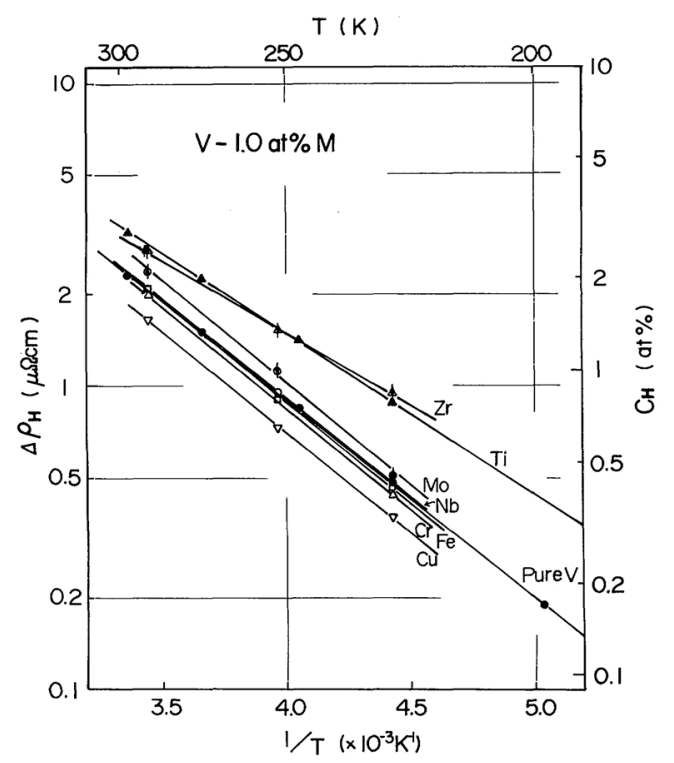

Fig. 5 The solid solubility of hydrogen in vanadium base 1 at. $\%$ alloys.

hand scale is calculated with $\rho_{\mathrm{H}}=1.12 \mu \Omega \mathrm{cm} /$ at $\% \mathrm{H}$ for all alloys including $\mathrm{V}-\mathrm{Zr}$ alloys. All the solubility curves are represented by an equation $C_{0} \exp (-\Delta H / k T)$ with different $C_{0}$ 's and $\Delta H$ 's. The effect of alloying on the solid solubility may be classified into four cases; (a) alloying considerably increases the hydrogen solubility ( $\mathrm{Ti}$ and probably $\mathrm{Zr}$ ), (b) slightly increases it (Mo), (c) has no effect $(\mathrm{Nb}, \mathrm{Cr}$ and $\mathrm{Fe}$ ) and (d) slightly decreases it $(\mathrm{Cu}) . \Delta H$ is the same as that in pure vanadium except for $\mathrm{V}-\mathrm{Ti}$ and $\mathrm{V}-\mathrm{Zr}$ alloys. Alloying other than $\mathrm{Ti}$ and $\mathrm{Zr}$ only affect $C_{0}$.

The dependence of hydrogen solubility on the $\mathrm{Ti}$ concentration at low $\mathrm{Ti}$ concentrations is shown in Fig. 6. There also exists a relationship $C_{0} \exp (-\Delta H / k T)$ in the range of temperatures investigated for each alloy, and both $C_{0}$ and $\Delta H$ decrease with increasing $\mathrm{Ti}$ concentration.

\section{Diffusivity}

The typical resistivity change caused by the hydrogen diffusion is shown in Fig. 7. This is the case of pure vanadium (MRC-V) at $273 \mathrm{~K}$. Positions of the spot-welded nickel potential leads are also indicated. As the hydrogen in the charged portion diffuses toward both ends, the resistivity of the section adjacent to the 


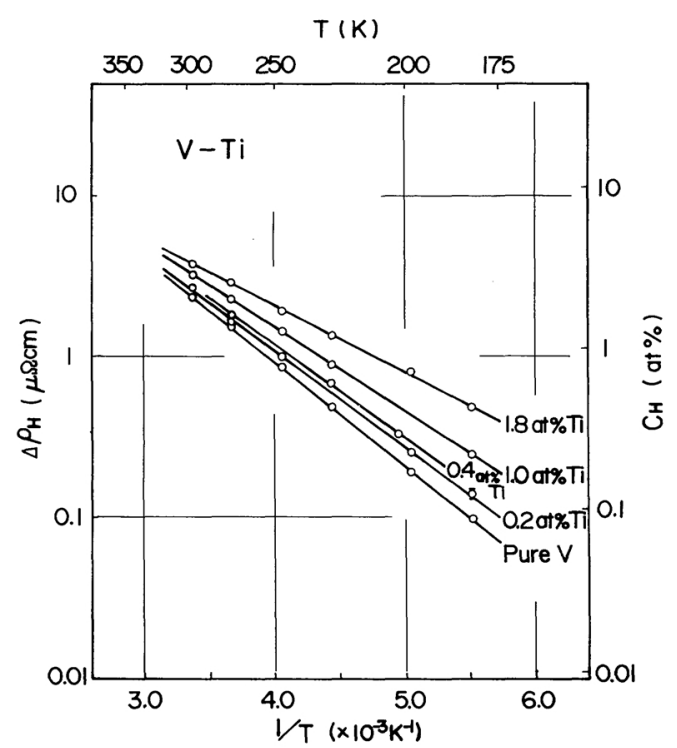

Fig. 6 The solid solubility of hydrogen in V-Ti alloys.

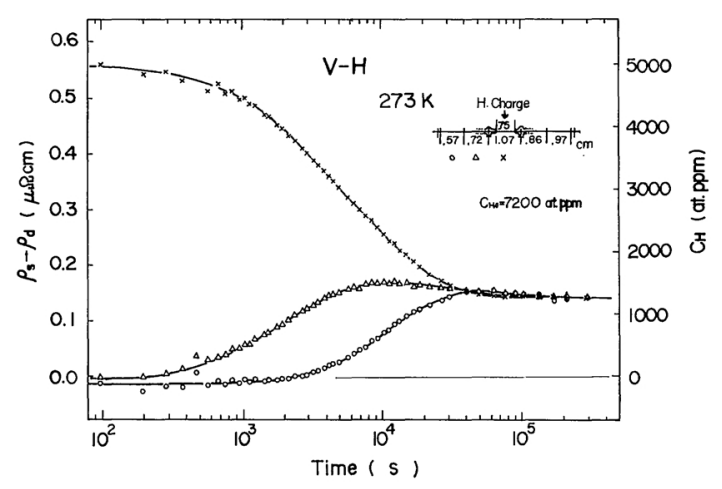

Fig. 7 The resistivity change with time due to the hydrogen diffusion in the pure vanadium at $273 \mathrm{~K}$. The configuration of the specimen is also shown in the figure.

charged portion increases, and those of the outer portions increase successively. Finally all parts of the specimen become of the same resistivity. It has been found by a separate experiment that no hydrogen escapes out of the specimen and the application of eqs. (2) (4) to the analysis of the diffusion data is justified.

The hydrogen diffusivity in vanadium of the two grades of purity are shown in Fig. 8 in the temperature range from $196 \mathrm{~K}$ to $365 \mathrm{~K}$. The two Arrhenius type plots agree with each other

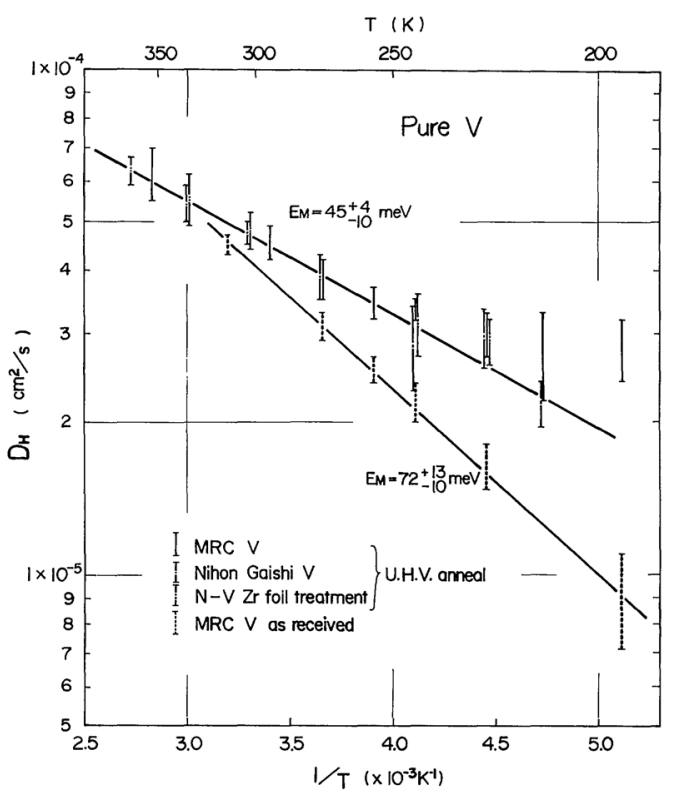

Fig. 8 Diffusivity of hydrogen in pure vanadium.

within the experimental accuracy, and give $D_{0}=(1.8$ to 3.1$) \times 10^{-4} \mathrm{~cm}^{2} / \mathrm{s}$ and $E=45_{-10}^{+4}$ $\mathrm{meV}$. The relatively large experimental error in the lower temperature region is due to small solid solubility at these temperatures. Diffusion measurement was also performed with an unannealed (as cold-worked) pure vanadium (MRC-V) and is shown in Fig. 8. The diffusivity is decreased and the activation energy for diffusion increases to $72 \pm 10 \mathrm{meV}$. In Table 3 are listed the hydrogen diffusion data in the present research as well as by other investigators in pure vanadium. The present results agree well with other results measured around room temperature by Gorsky effect ${ }^{(14)(15)}$ and resistivity change method ${ }^{(7)}$.

Diffusion coefficients in $\mathrm{V}-1.0$ at $\%$ transition metal alloys are shown in Fig. 9. Addition of $\mathrm{Ti}$ retards the hydrogen diffusion, while other alloying elements, except $\mathrm{Zr}$, have no effect on it. Since Ti is found to be the most effective alloying element to decrease hydrogen diffusion, the $\mathrm{Ti}$ concentration dependence of the diffusion coefficient is investigated most extensively. Figure 10 shows the hydrogen diffusivity at $273 \mathrm{~K}$ for various alloying concentration in $\mathrm{V}-\mathrm{Ti}$ and other alloys. Addition of 5 at $\% \mathrm{Ti}$ decreases the hydrogen diffusion coefficient to one tenth of that in the pure 
Table 3 Hydrogen diffusion parameters in pure vanadium.

\begin{tabular}{lcccccc}
\hline & \multicolumn{1}{c}{$D_{\mathrm{o}}\left(\mathrm{cm}^{2} / \mathrm{s}\right)$} & $\begin{array}{c}E \\
(\mathrm{meV})\end{array}$ & $\begin{array}{c}\text { Temp. } \\
\text { range }(\mathrm{K})\end{array}$ & $\begin{array}{c}C_{H} \text { range } \\
(\text { at } \%)\end{array}$ & $\begin{array}{c}\text { Experimental } \\
\text { technique }\end{array}$ & Ref. \\
\hline Present work & $(1.8 \sim 3.1) \times 10^{-4}$ & $45_{-10}^{+4}$ & $196 \sim 365$ & $\mathbf{0 . 1} \sim 1.2^{*}$ & resistometry & \\
Völkl et al. $(1977)$ & $(3.1 \pm 0.5) \times 10^{-4}$ & $45 \pm 4$ & $145 \sim 575$ & & Gorsky effect & $(14)$ \\
Cantelli et al. $(1970)$ & $(4.4 \pm 1.5) \times 10^{-4}$ & $59 \pm 7$ & $185 \sim 400$ & & Gorsky effect & $(15)$ \\
Heller \& Wipf $(1976)$ & $1.8 \times 10^{-4 * *}$ & $40 \pm 5$ & $175 \sim 320$ & $0.044 \sim 1.29$ & resistivity change & $(7)$ \\
Eguchi \& Morozumi $(1977)$ & $8.8 \times 10^{-4}$ & $110 \pm 3$ & $813 \sim 1373$ & & absorption & $(3)$ \\
Boes \& Züchner (1976) & $(4.3 \pm 1.4) \times 10^{-4}$ & $63 \pm 7$ & $273 \sim 373$ & & electrochemical & $(16)$ \\
\hline
\end{tabular}

* charged hydrogen concentration.

** This $D_{0}$ value is for the hydrogen concentration of 0.044 at $\%$.

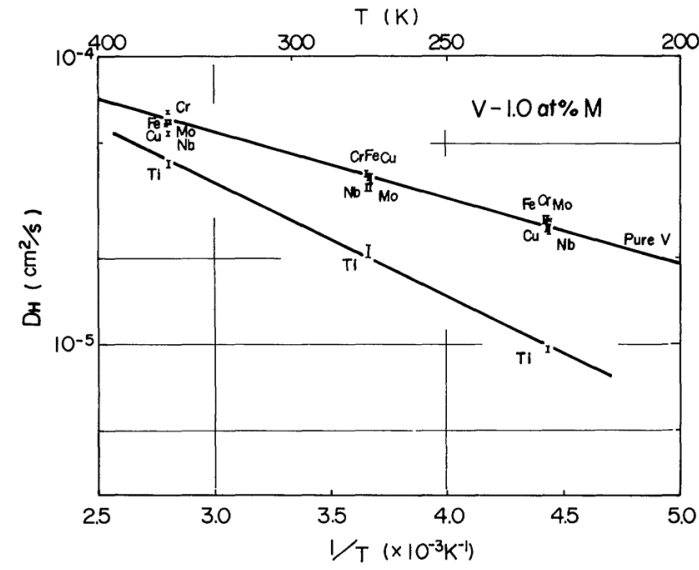

Fig. 9 Diffusivity of hydrogen in vanadium base 1 at $\%$ alloys.

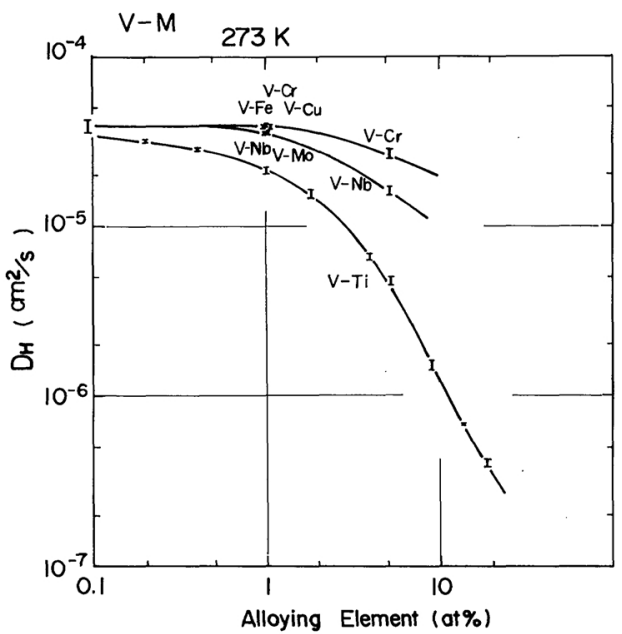

Fig. 10 The alloying concentration dependence of the diffusivity of hydrogen in vanadium base alloys at $273 \mathrm{~K}$.

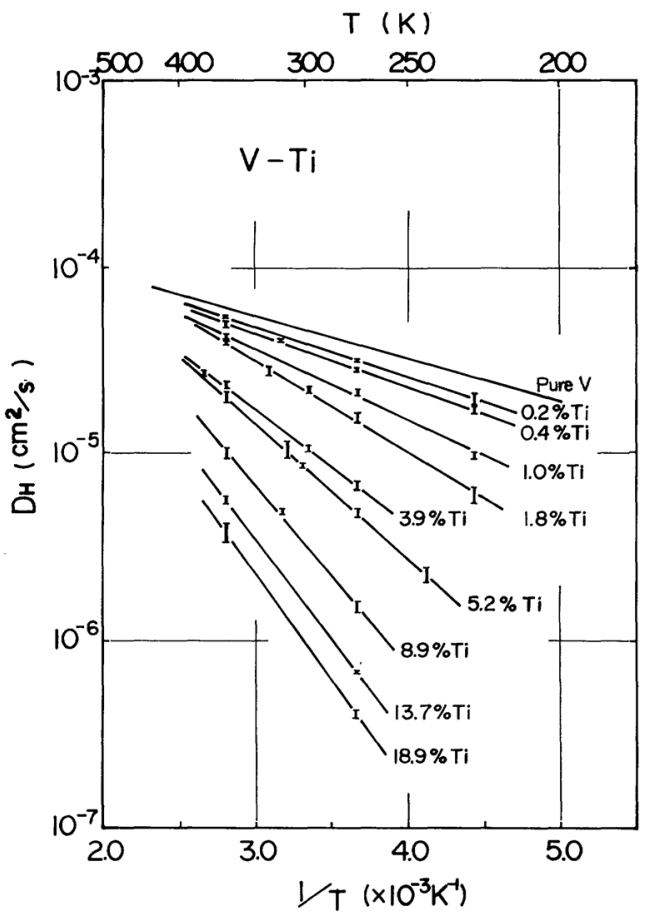

Fig. 11 Arrhenius plot of the diffusivity of hydrogen in vanadium-titanium alloys.

vanadium at $273 \mathrm{~K}$. Temperature dependence of the diffusion coefficients in various $\mathrm{V}-\mathrm{Ti}$ alloys are shown in Fig. 11. They are represented by an Arrhenius type equation for each alloy. $D_{0}$ 's and $E$ 's are obtained and shown in Fig. 12. They increase monotonically with the $\mathrm{Ti}$ concentration, and saturate at about 10 at $\% \mathrm{Ti}$ to values of $5 \times 10^{-3} \mathrm{~cm}^{2} / \mathrm{s}$ and $210 \mathrm{meV}$, respectively.

In $\mathrm{V}-\mathrm{Zr}$ alloy the resistivity change during diffusion anneal occurs slowly and lasts for an extraordinarily long time. The whole experi- 


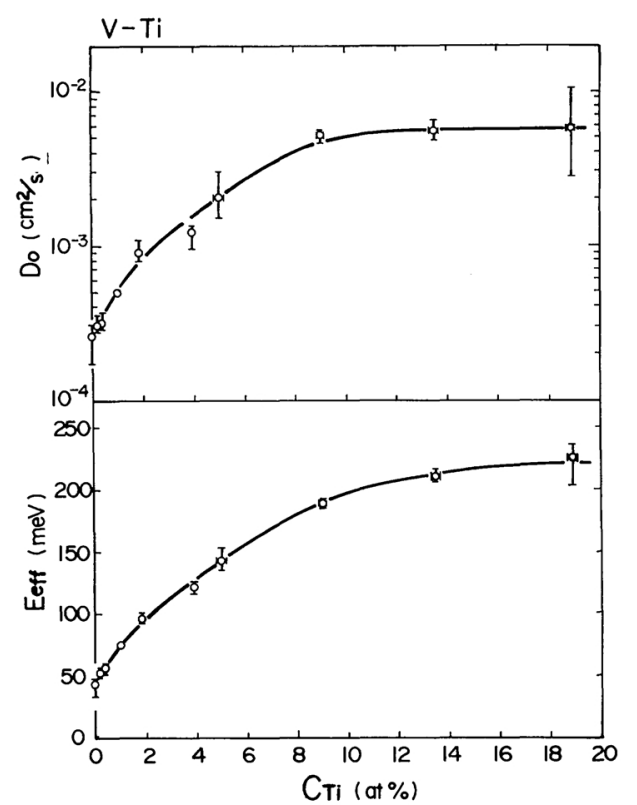

Fig. 12 The titanium concentration dependence of the pre-exponential factor $D_{0}$ and the activation energy $E_{\text {eff }}$.

mental curve cannot be fitted to a calculated one with single diffusion coefficient. Although an accurate determination of the diffusion coefficient is impossible, the diffusivity seems to be decreased by $\mathrm{Zr}$ addition.

\section{Discussion}

\section{Solid solubility}

Although the specimen is surrounded by hydrogen gas during measurement, the solubility determined by the present technique is not the gas solubility limit, but that in equilibrium with hydrides. This is so, because when hydrogen is charged electrolytically very thin hydride layer is formed on the surface ${ }^{(26)}$. The fact that the present results agree well with the solubility in equilibrium with hydride measured by other investigators verifies this consideration.

The effect of alloying is discussed by comparing the present results with the solubility measured at high temperatures ${ }^{(2)}$. At high temperatures the added elements affect only the energy of hydrogen in solid solution, because

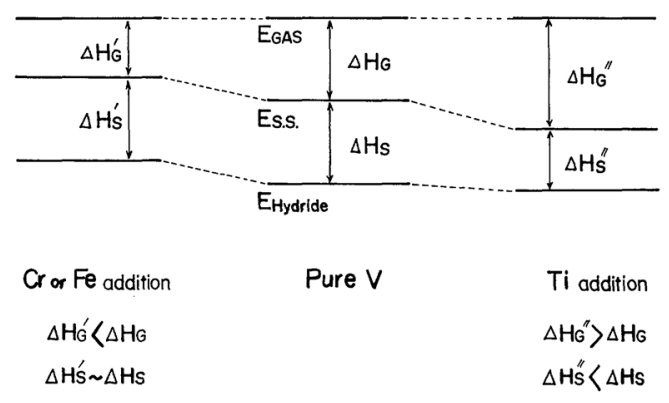

Fig. 13 Schematic illustration of hydrogen energy levels in the various phases and the effect of alloying on the levels.

hydrogen in solid solution is in equilibrium with the gas phase. On the other hand, they may affect the energy of hydrogen both in solid solution and hydride at low temperatures where hydrogen in solid solution is in equilibrium with hydride. At high temperatures the addition of $\mathrm{Ti}$ increases both the gas solubility and the heat of solution, $\Delta H_{\mathrm{G}}$. On the contrary, at low temperatures the addition of $\mathrm{Ti}$ decreases the heat of solution, $\Delta H_{\mathrm{S}}$, and increases the solid solubility. In the case of addition of $\mathrm{Cr}$ or $\mathrm{Fe}$, both the gas solubility and $\Delta H_{\mathrm{G}}$ are decreased, but the solid solubility or $\Delta H_{\mathrm{S}}$ is unaffected. Figure 13 schematically shows the relative positions of the hydrogen energy levels in the gas phase, solid solution and hydride, and the effect of alloying on them. Addition of $\mathrm{Ti}$ decreases the hydrogen energy in solid solution, but its effect on the energy in hydride is not known. If the energy in hydride is affected, the effect should be such to decrease $\Delta H_{\mathrm{S}}$. Addition of $\mathrm{Cr}$ or $\mathrm{Fe}$ increases the hydrogen energy in solid solution. Since $\mathrm{Cr}$ and $\mathrm{Fe}$ do not change $\Delta H_{\mathrm{S}}$, the energy in hydride should also be increased. Since titanium gives the most pronounced effect, it will be further discussed later in terms of the hydrogentitanium interaction.

\section{Diffusivity}

The dependence of diffusion coefficient on the hydrogen concentration was observed by Heller and $\operatorname{Wipf}^{(7)}$ between 0.044 and 1.29 at $\% \mathrm{H}$. In the present experiment, the hydrogen diffusion coefficient is independent of the charged hydrogen concentration between 0.1 
at $\%$ and 1.2 at $\%$ in pure vanadium at $273 \mathrm{~K}$. The charged hydrogen concentration is measured at the central portion, of which length is about one tenth of the whole specimen length. Hence, the hydrogen concentration in other portions than the central portion is at most 0.12 at $\%$. The hydrogen diffusion is measured at concentrations much smaller than 0.12 at $\%$. This is the reason why the concentration dependence of the hydrogen diffusion is not found in the present experiment.

When the present diffusion data measured near room temperature are extrapolated to the higher temperature range, they do not agree with the high temperature data except for V-Ti alloy as shown in Fig. 14. Note that specimens in both experiments are taken from the same alloy. It is possible that the experimental error in the near room temperature measurements may cause an appreciable error when extrapolated. Even if this error is taken into account, the activation energy for the diffusion, i.e., the slope of the lines, does not agree between the high temperature and the

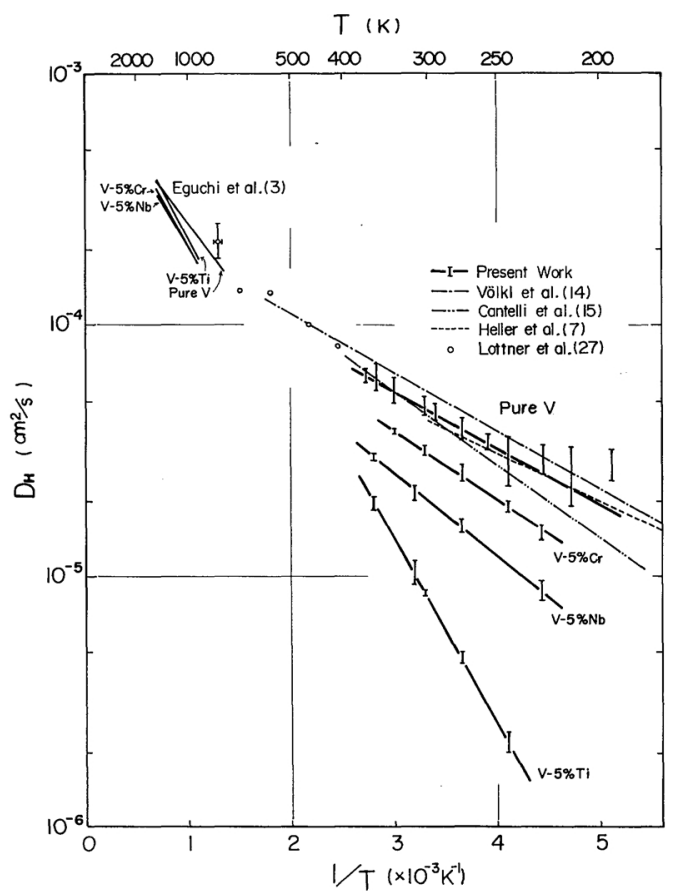

Fig. 14 Diffusivity of hydrogen in pure vanadium and vanadium base 5 at \% alloys as compared with the high temperature data. near room temperature data except for $\mathrm{V}-\mathrm{Ti}$ alloy. The Arrhenius type plot is concave downward between room temperature and temperatures near the melting point. Recently Lottner, Heim and Springer ${ }^{(27)}$ have reported the hydrogen diffusion coefficient measured by quasielastic neutron scattering technique. The data show a similar deviation from the Arrhenius type plot between 408 and $773 \mathrm{~K}$. A similarly curved Arrhenius relation is also observed in other interstitial atom diffusion in $\mathrm{BCC}$ metals, e.g., $\mathrm{C}$ in $\mathrm{Mo}^{(28)}, \mathrm{N}$ in $\mathrm{Mo}^{(29)}$ and $\mathrm{C}$ in $\mathrm{Fe}^{(30)}$ in the similar temperature range. A deviation from the Arrhenius relation also exists in hydrogen diffusion in $\mathrm{Nb}$ and $\mathrm{Ta}$ below room temperature ${ }^{(14)}$. This anomaly is considered to be originated from the characteristics of hydrogen. Since the present anomaly is found at far above room temperature, it is considered to be originated from the nature of vanadium and not from the characteristics of hydrogen. Several mechanisms have been proposed for this sort of anomaly ${ }^{(30)}$, but the problem is not completely solved as yet. In the case of $\mathrm{V}-\mathrm{Ti}$ alloy, $\mathrm{Ti}$ causes such a strong effect on the hydrogen diffusion that the effect of $\mathrm{V}$ metal itself seems to be masked.

\section{V-Ti alloys}

The reduction of the hydrogen diffusivity by Ti addition may be due to hydrogen trapping by $\mathrm{Ti}$ atoms, especially at low $\mathrm{Ti}$ concentration range. The effect of trapping in the hydrogen diffusion is often observed in iron and steels ${ }^{(31)}$. The binding energy, $B$, between a titanium atom and a hydrogen atom may be calculated with the Oriani equation ${ }^{(32)}$,

$$
\begin{aligned}
& D_{\text {eff }}=D_{\mathrm{L}}\left\{1+\frac{N_{\mathrm{T}} N_{\mathrm{L}} K}{\left(N_{\mathrm{L}}+K C_{\mathrm{L}}\right)^{2}}\right\}^{-1}, \\
& K=\exp \left(\frac{B}{k T}\right),
\end{aligned}
$$

where $D_{\text {eff }}, D_{\mathrm{L}}, N_{\mathrm{T}}, N_{\mathrm{L}}$ and $C_{\mathrm{L}}$ are the apparent diffusivity, the diffusivity in the free lattice, the number of trap sites and normal lattice sites, and the hydrogen concentration on normal lattice sites respectively. Here, it is assumed that the traps, i.e., titanium atoms, are randomly distributed, and each titanium atom traps only 


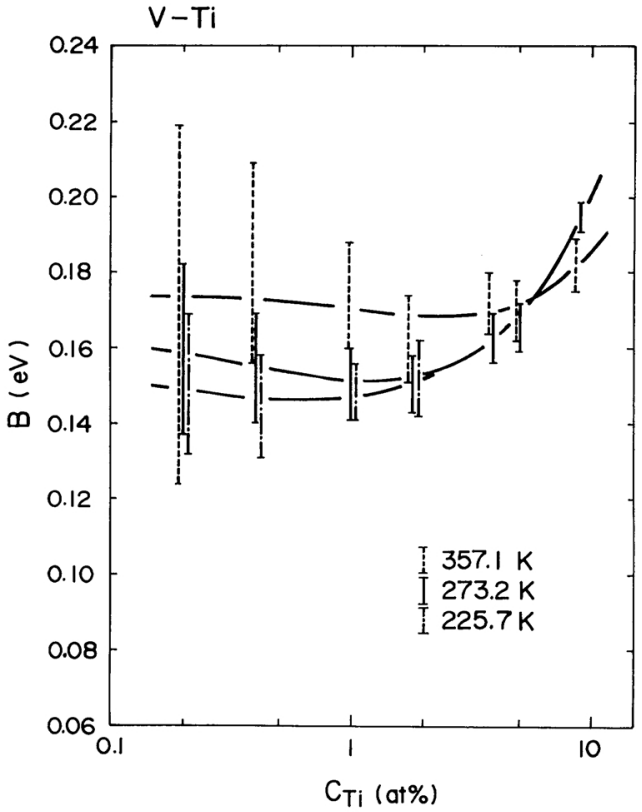

Fig. 15 Titanium concentration dependence of the binding energy between a hydrogen atom and a titanium atom calculated by eq. (5) and (6) at three temperatures.

one hydrogen atom at a time. The estimated binding energy is shown in Fig. 15. It is about $0.15 \mathrm{eV}$ at low $\mathrm{Ti}$ concentrations. The values at three temperatures are considered to agree with each other, if the error is taken into account. However, it increases with Ti concentration $(>4$ at $\%$ ). This $\mathrm{Ti}$ concentration dependence shows that the trap model is not adequate for high $\mathrm{Ti}$ concentrations. The assumption that $\mathrm{Ti}$ atoms are isolated and dispersed randomly seems to be invalid for high $\mathrm{Ti}$ concentrations, i.e., more than about 4 at $\%$.

The increase in solid solubility may also be due to the trapping effect, which effectively reduces the hydrogen energy level in solid solution. The total hydrogen concentration in solid solution with traps is expressed as follows ${ }^{(33)}$ with $C_{\mathrm{Ti}}$ the Ti concentration;

$$
C_{\mathrm{H}}=C_{\mathrm{F}}+C_{\mathrm{T}}=C_{\mathrm{F}}+\frac{4 C_{\mathrm{Ti}} C_{\mathrm{F}} \exp \left(\frac{B}{k T}\right)}{1+4 C_{\mathrm{F}} \exp \left(\frac{B}{k T}\right)},
$$

where $C_{\mathrm{H}}, C_{\mathrm{F}}$ and $C_{\mathrm{T}}$ denote the total, the free

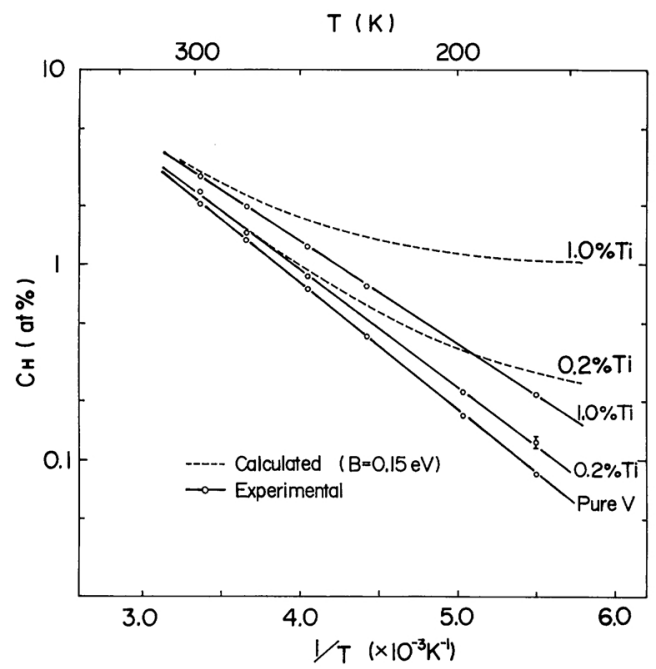

Fig. 16 The hydrogen solubility curves calculated with eq. (7) and experimental curves.

and the trapped hydrogen concentration, respectively. Here again, the same assumptions are made for traps as in the diffusion coefficient. The solid solubility curve is calculated with the binding energy, $0.15 \mathrm{eV}$, obtained from the diffusion data, and illustrated in Fig. 16. The calculated curve is compared with the experimental curve, with an assumption that the trapped hydrogen has the same contribution to the resistivity as that on the free sites. There is a discrepancy between the calculated solubility and the observed one, especially in the low temperature region. This descrepancy may be removed by assuming that the resistivity of a hydrogen-titanium pair is less than $60 \%$ of the sum of resistivities due to isolated hydrogen and titanium atoms. This assumption would be reasonable.

Electronmicroscopy, polarized optical microscopy or X-ray diffraction could not reveal clusters or precipitates of titanium. To examine whether or not the concentration fluctuation of alloying element exists, EPMA analysis was performed for all alloys. Line distributions of alloying element measured by the characteristic X-ray are shown in Fig. 17. Alloying elements except $\mathrm{Ti}$ and $\mathrm{Zr}$ may be considered to be homogeneously distributed. The concentration of $\mathrm{Ti}$ may be regarded as being homogeneous up to $1.8 \mathrm{at} \% \mathrm{Ti}$, but fluctuates 
$V-T i$

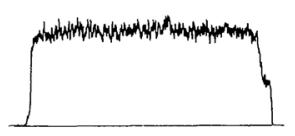

$1.0 \%$

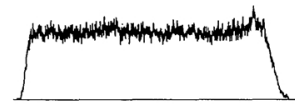

$1.8 \%$

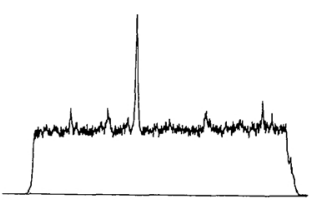

$3.9 \%$

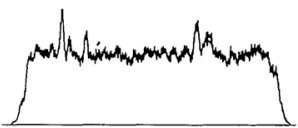

$5.2 \%$

$\overline{20 \mu m}$

Fig. 17 Distribution of alloying element in various alloys measured with EPMA line analysis.

considerably when the concentration increases beyond 3.9 at $\%$. The concentration of 3.9 at $\% \mathrm{Ti}$ is that at which the apparent binding energy begins to increase. In $\mathrm{V}-1.0$ at $\% \mathrm{Zr}$, there also exists a marked concentration fluctuation. These segregation may be the main cause of the deviation of hydrogen diffusivity from the simple trap model, and the apparently low $\rho_{\mathrm{H}}$ value in $\mathrm{V}-\mathrm{Zr}$ alloys, i.e., hydrogen trapped at clusters of $\mathrm{Zr}$ atoms would contribute much less to the resistivity than hydrogen trapped by isolated $\mathrm{Zr}$ atoms.

The origin of the hydrogen-solute atom interaction has often been related to the lattice parameter change ${ }^{(34)}$; the elastic strain around solute atoms is considered to be the origin of the binding. X-ray measurement gives, however, no systematic relation between the lattice parameter change by alloying and the hydrogen

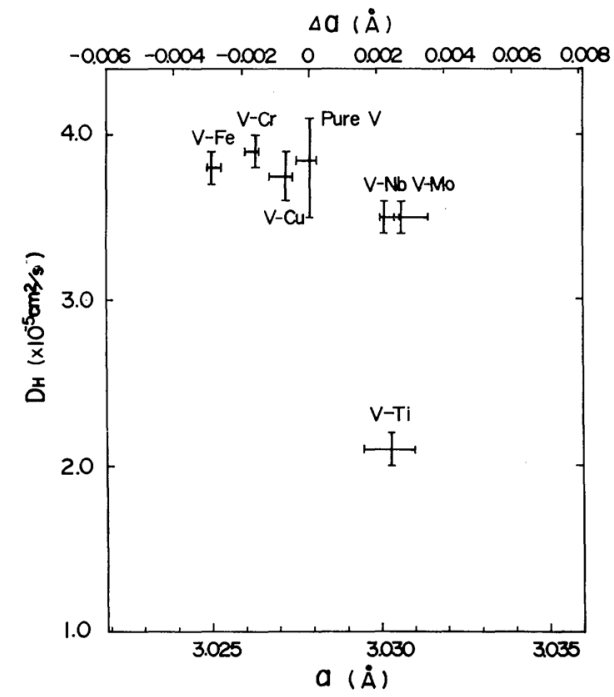

Fig. 18 Relation between the change in lattice parameter due to alloying and the diffusivity of hydrogen in 1 at $\%$ alloys at $273 \mathrm{~K}$.

diffusivity at $273 \mathrm{~K}$, as shown in Fig. 18 . Titanium and zirconium are in the left side group of the solvent element, vanadium, on the periodic table. Their addition causes large decreases in the hydrogen diffusion and large increases in the hydrogen solid solubility. A similar relation between solute and solvent is observed in other alloy systems, e.g., the $\mathrm{Rh}$ addition to $\mathrm{Pd}^{(35)}$ and the $\mathrm{Cr}$ addition to $\mathrm{Fe}^{(36)}$. Therefore, the origin of the binding may be electronic.

\section{Conclusion}

The solid solubility in equilibrium with hydride and the diffusion coefficient of hydrogen near room temperature are measured in pure vanadium and various vanadium alloys, and the followings are found:

(1) The solid solubility is increased by the addition of $\mathrm{Ti}$ and $\mathrm{Zr}$, slightly increased by $\mathrm{Mo}$, not affected by $\mathrm{Nb}, \mathrm{Cr}$ or $\mathrm{Fe}$ and slightly decreased by $\mathrm{Cu}$.

(2) The diffusion coefficient is decreased by the addition of $\mathrm{Ti}$ and $\mathrm{Zr}$, while other alloying elements, $\mathrm{Mo}, \mathrm{Nb}, \mathrm{Cr}, \mathrm{Fe}$ and $\mathrm{Cu}$, have no effect on it.

(3) The effects of $\mathrm{Ti}$ and $\mathrm{Zr}$ on the hydrogen solubility and diffusion may be due to binding 
between hydrogen atoms and atoms of these alloying elements, when the alloy concentration is less than about $4 \%$. The hydrogen-titanium binding energy is estimated to be about 0.15 $\mathrm{eV}$ for dilute $\mathrm{V}-\mathrm{Ti}$ alloys. The origin of the hydrogen-titanium and hydrogen-zirconium binding are likely to be electronic.

\section{Acknowledgments}

The $\mathrm{V}-5$ at $\% \mathrm{Ti}, \mathrm{Cr}$ and $\mathrm{Nb}$ alloys were offered by Professor Morozumi and Dr. Eguchi, to whom the authors express their hearty thanks. Other alloys were melted by Mr. Ono and Mr. Yamada. Hydrogen analysis was performed by Mr. Hosoya, the EPMA by Mr. Oki and Mr. Sato. The authors are grateful to all of them for their co-operation. Thanks are also due to Prof. Hirabayashi for his permission to use the X-ray equipment in his group.

\section{REFERENCES}

(1) R. K. Edwards and E. Veleckis: Metal Hydrides, Ed. by W. M. Mueller, J. P. Blackledge and G. G. Libowitz, Academic Press, New York and London, (1968), p. 601.

(2) T. Eguchi and S. Morozumi: J. Japan Inst. Metals, 38 (1974), 1025.

(3) T. Eguchi and S. Morozumi: ibid., 41 (1977), 795.

(4) J. Friedel: Ber. Bunsenges. Phys. Chem., 76 (1972), 828.

(5) D. G. Westlake: Trans. ASM, 62 (1969), 1000.

(6) S. Takano and T. Suzuki: Acta Met., 22 (1974), 265.

(7) R. Heller and H. Wipf: Phys. Status Solidi, (a), 33 (1976), 525.

(8) D. G. Westlake: Trans. Met. Soc. AIME, 239 (1967), 1341.

(9) C. V. Owen, D. H. Sherman and T. E. Scott: ibid., 239 (1967), 1666.

(10) F. Abe, R. Hanada and H. Kimura: 2nd Int. Cong. on Hydrogen in Met. (Paris), (1977), $1 \mathrm{~B} 7$.

(11) H. Y. Chang and C. Wert: Acta Met., 21 (1973), 1233.

(12) R. Cannelli and F. M. Mazzolai: Appl. Phys., 1 (1973), 111.
(13) O. Yoshinari, M. Koiwa, H. Asano and M. Hirabayashi: Trans. JIM, 19 (1978), 171.

(14) J. Völk1, H. C. Bauer, U. Freudenberg, M. Kokkinidis, G. Lang, K. -A. Steinhauser and G. Alefeld: Proc. 6th Int. Conf. Internal Friction and Ultrasonic Attenuation in Solids (Tokyo), (1977), p. 485.

(15) R. Cantelli, F. M. Mazzolai and M. Nuovo: J. Phys. Chem. Solids, 31 (1970), 1811.

(16) N. Boes and H. Züchner: Z. Naturforsch., 31a (1976), 760.

(17) K. Abe, K. Toma, H. Yoshinaga and S. Morozumi: J. Less-Common Metals, 23 (1971), 213.

(18) E. Lang and J. Bressers: Z. Metallk., 67 (1976), 66.

(19) M. Hosoya: Sci. Rep. RITU A, 22 (1971), 183.

(20) D. G. Westlake, S. T. Ockers and D. W. Regan: J. Less-Common Metals, 49 (1976), 341.

(21) B. A. Merisov, V. I. Khotkevich and A. I. Karnus: Phys. Metals Metallogr., 22 (1966), 163.

(22) J. Crank: The Mathematics of Diffusion, 2nd ed., Clarendon Press, Oxford, (1975), p. 16.

(23) W. Maier and H. Wipf: Scripta Met., 11 (1977), 695.

(24) D. T. Peterson and C. L. Jensen: Met. Trans., 9A (1978), 1673.

(25) K. Watanabe and Y. Fukai: private communication.

(26) Y. Sasaki and M. Amano: Trans. JIM, 8 (1967), 276.

(27) V. Lottner, A. Heim and T. Springer: Z. Physik B, 32 (1979), 157.

(28) H. Kimura and K. Yoshioka: Mater. Sci. Eng., 24 (1976), 171.

(29) J. H. Evans, B. L. Erye and H. K. Birnbaum: Acta Met.,18 (1970), 835.

(30) C. G. Homan: Acta Met., 12 (1964), 1071.

(31) L. S. Darken and R. P. Smith: Corrosion, 5 (1949), 1.

(32) R. A. Oriani: Acta Met., 18 (1970), 147.

(33) G. Pfeiffer and H. Wipf: J. Phys. F., 6 (1976), 167.

(34) T. Matsumoto, Y. Sasaki and M. Hihara: J. Phys. Chem. Solids, 36 (1975), 215.

(35) D. Artmann and Ted B. Flanagan: J. Phys. Chem., 77 (1973), 2804.

(36) J. O'M. Bockris, M. A. Genshaw and M. A. Fullenwider: Electrochim. Acta, 15 (1970), 47. 